\title{
COMPLEX EVALUATION OF SAFETY CULTURE DETERMINANTS IN MANUFACTURING COMPANIES IN SLOVAKIA
}

\author{
Erika SUJOVÁ, Helena ČIERNA \\ Technical University in Zvolen
}

\begin{abstract}
:
The paper addresses complex evaluation of safety culture in Slovak manufacturing enterprises by utilizing specific determinants. To accommodate conditions of enterprises in Slovakia, a specific research method was developed for the study of safety culture, which can also be used for manufacturing and non-manufacturing enterprises. We have selected the questionnaire method. Due to the scope of the research, we have defined ten determinants, which form the basis for evaluation of safety culture elements. When determining the level of the specific ten determinants of safety culture, we studied interdependence between the enterprise's industry, its size (small, medium, large) and points assigned to each determinant. The results of the study are evaluated using a 3D point graph. The discussion shows parts that were evaluated the highest or lowest and outlines suggested approaches to improve the current state.
\end{abstract}

Key words: evaluation of enterprises, questionnaire method, safety culture

\section{INTRODUCTION}

Occupational health and safety, and work conditions are becoming an important aspect of evaluation of an enterprise with direct influences on productivity, effectiveness, and quality of work and the enterprise's productivity as a whole. By maintaining a good level of Occupational Health and Safety (OHS), an enterprise can prevent irreplaceable loss of life and can eliminate work accidents, work-related illnesses and other work-related health risks. The economic effect is however the most noticeable in processes that lead to improvement of safety and protection of health at work as well as in improvement of working conditions and leads to optimization of working processes, decrease in losses, higher productivity, effectiveness, quality of work, to higher prosperity of business and the enterprise as a whole $[1,6]$.

Safety culture is defined as a collection of processes, individual approaches and thinking of people. It ensures that safety issues are given a higher priority, corresponding to their importance. There are two basic approached to research of level of safety culture in enterprises. The first approach is based on statistical data, noted facts about safety, relevant safety indicators, so called matrices. As part of this approach, enterprises evaluate the level of their safety culture quantitatively based on empiric data from multi-year research. The second approach is so called qualitative approach, which utilizes survey-based research in which respondents evaluate selected indicators of safety culture according to their subjective opinion about a given area in their place of work. This approach is recommended for new organizations that do not have required data for quantitative evaluation, or for smaller enterprises.

The paper discusses evaluation of safety culture in specific industrial organizations in Slovakia. We used the surveybased research method in which respondents evaluated level of ten determinants of safety culture, by answering a group of thirty questions. Results of the research showed in which areas organizations have a strong or a stable position and were improvement is required. This article is part of a grant project KEGA, no. 011TU Z-4/2017 „Integration of progressive information technology and soft-skills in study programs focusing on management of production processes."

\section{CHARACTERIZATION OF THE TERM „SAFETY CULTURE“ AND RELATED RESEARCH}

Safety culture is characterized by the level of true fulfillment and identification with goals and tasks in safety. It represents symmetry of what is declared in terms of safety policies, internal regulations and work processes and how it really works in an organization when ensuring safety as part of daily processes.

HSE characterizes safety culture in an organization as a result of group understanding of competencies, model behaviour of responsibilities, style and professional adaptability of management of an organization. Organizations with a positive safety culture communicate 
based on mutual trust and share perceived importance of safety and trust in effectiveness of prevention [4].

IAEA states that safety culture is a diagram of characteristics and approaches in an organization and individuals that determine that the main priority are questions of safety in the organization, and as such they receive attention that ensures their importance [3].

Organizations with high safety culture and with developed understanding of safety at work have the following characteristics:

- Symmetry between official statements and daily work.

- Direct and open approach to weak areas, approaches that focus on finding a solution.

- Move away from culture of finger pointing.

- Employees and management act responsibly, independently, with a team focus. Safety culture is part of their daily life.

- Safety standards are accepted and integrated into daily activities.

- Safety and health safety are highly regarded by employees and by the organization as a whole.

- All levels of management and employees are actively involved in safety.

Nowadays, research related to safety culture is performed to gain understanding of its scope and components and the relationship between safety culture and operational safety. There are many approaches how safety culture can be measured. These differ in terms of statistical criteria, detail of analysis, economic advantages or their use. Safety is studied in relation to several factors, however mainly for various industries, different approaches by management and various problems [2, 8]. The highest level of culture is implicit common understanding among people within a team and the entire organization. Approaches and believes can change behaviours, which can lead to potential problems.

There are many methods and criteria for objective evaluation of organizational processes that lead to the optimal set up of safety culture. Their use depends on specific characteristics of the evaluated organization, requirements of the industry and implemented safety management systems. There are many approaches to measuring safety culture, they differ in terms of statistical criteria, detail of analysis, economic advantages and use [7]. Each study defines elements of safety culture differently. The reason for this differentiation is due to the difference of studied elements. Safety is studied in terms of several factors, specifically for different industries, different directions of management and other potential problems [3]. Different evaluations, different kinds of surveys and methods of evaluation lead to incomparable results, since they result from different criteria. We believe that application of any evaluation method of specific conditions of an organization is possible once methods are adapted to existing conditions and evaluated priority determinants are determined. A positive example of motivation of organizations to evaluate the level of safety culture in their organization is the 'Safety Culture Award'which is a national event.

\section{SPECIFICATIONS OF DETERMINANTS AND RESEARCH} METHOD

The goal of the research was to evaluate levels of safety culture in Slovak enterprises. We selected the surveybased research method, which is used for given character of research goals. The basis of the research was not to evaluate compliance with legislation, which is mandatory for all employees. The goal was to determine, with the help of evaluation of specific areas, determinants, and the use of well defined questions, whether outlined areas are implemented in companies' processes on an informal basis, that is whether they are an integral part of safety culture in researched enterprises.

Based on study of available literature, expert views and acceptance of specific conditions in the analyzed country, to evaluate the level of safety culture in Slovak enterprises, we have selected ten determinants that form the basis of evaluation of elements of safety culture. Determinants of safety culture are based on current legislation in Slovakia, specifically Act no. 124/2006 Coll. about safety and protection of health at work in later regulations. To evaluate levels, we specified the following determinants of safety culture, which are relevant for evaluation:

1. Company's policies.

2. Safety processes.

3. Motivation for OHS.

4. Education about OHS.

5. Communication.

6. Employee involvement.

7. Management's involvement.

8. Management's responsibility.

9. Ensuring safety.

10. Contribution to safety.

For the survey, we used above-mentioned ten determinants which consisted of thirty questions - each determinant had three questions. The goal of the questions was to evaluate whether level in a specific area is sufficient, how respondents perceive completion of tasks and responsibilities and whether they actively contribute to safety at their place of work.

To evaluate answers to individual questions, we used Likert's evaluation scale, represented by point evaluation, as seen in Tab. 1. Each respondent selected in each question one phrase, however during evaluation the corresponding number was used for calculation.

Table 1

Likert's evaluation scale

\begin{tabular}{lccccc}
\hline Phrase & $\begin{array}{c}\text { Highly } \\
\text { disagree }\end{array}$ & $\begin{array}{c}\text { Disa- } \\
\text { gree }\end{array}$ & $\begin{array}{c}\text { Cannot } \\
\text { evalu- } \\
\text { ate }\end{array}$ & Agree & $\begin{array}{c}\text { Com- } \\
\text { pletely } \\
\text { agree }\end{array}$ \\
\hline $\begin{array}{l}\text { Point } \\
\text { evaluation }\end{array}$ & 1 & 2 & 3 & 4 & 5 \\
\hline
\end{tabular}

The structure of the survey was created based on identification of determinants and their specification with the help of questions and Likert's evaluation scale, which was transferred into electronic form. For online publication of the survey, we used a web application www.iankety.sk. Here we programmed individual questions to evaluate the level of safety culture. 


\section{Analysis of Respondents}

After creation of the survey, it was disseminated to the appropriate parties. We emailed the selected respondents a request to participate in research regarding the level of safety culture, which included a specific online code of the survey and respondents could with the code directly connect to the survey online and complete it. We emailed the survey to 256 potential respondents, to companies operating in Slovakia. We received responses from 74 respondents. The rate of return of the survey was $28.9 \%$, which is quite low. This low rate of return means that enterprises are not willing to evaluate their level of safety, potentially due to concerns about unfavorable results. Once the survey was completed, respondents were grouped based on industry of their organization, size, number of employees, region based on municipalities and based on respondent's position in the organization.

Industries in which enterprises operate were divided into:

- Manufacturing engineering enterprises,

- Other manufacturing (not engineering) enterprises,

- Non-manufacturing enterprises.

After analysis of respondents based on industry (Figure 1), we have determined that most represented were manufacturing enterprises in mechanical engineering, 38\%, followed by other manufacturing enterprises and non-manufacturing enterprises. We can state that the all three industries are represented fairly similarly.

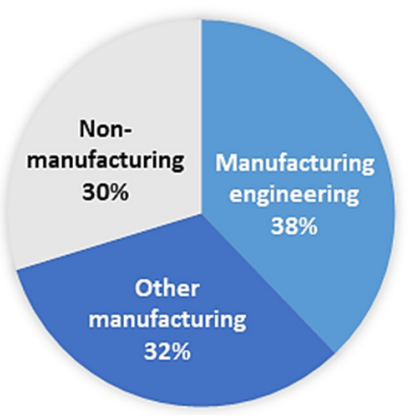

Fig. 1 Analysis of Respondents based on industry

The enterprises were divided based on size, specifically number of employees:

- large - more than 250 employees (indicated as L)

- medium - 50 - 249 employees (indicated as M)

- small - up to 49 employees (indicated as S)

Analysis of respondents in terms of company size (Figure 2) showed that the largest representation had small enterprises, 35\%. We can state that all companies had similar representation, between $31-35 \%$.

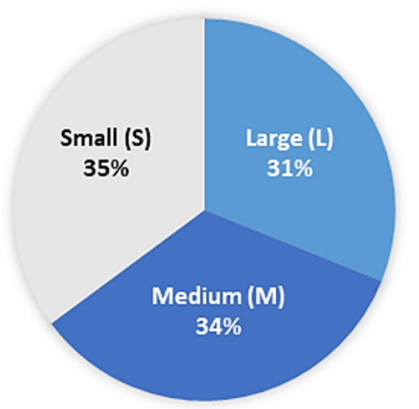

Fig. 2 Analysis of respondents based on company size

\section{RESULTS AND EVALUATION OF THE RESEARCH}

The results of the research were evaluated in software called STATISTICE (version 10). For visual representation of relationship between individual values we chose to show these on point graphs. We assumed that points assigned by individual respondents to individual determinants are clearly represented by arithmetic averages of assigned points and their visual representation is clear. The graphs allow for easy comparison of individual evaluated categories. For comparison of relationships between complex evaluations of levels of all ten determinants of safety culture in a specific industry and its size, specifically respondent's position in the company, was shown in 3D point graphs. To show the level of a specific determinant of safety culture in specific industry, we used 2D point graphs categorized based on size.

When evaluating levels of the tem determinants of safety culture, which was based on the enterprise's characteristics, we looked for relationships between the company's industry (manufacturing, mechanical engineering or nonmanufacturing), size of the company (small, medium, large) and points assigned to individual determinants. We assumed that in manufacturing enterprises work processes are more complicated, in terms of ensuring safety at work, which should be reflected in the level of their safety culture. We also assumed that enterprises with smaller number of employees should have their OHS management processes better set up, which should be reflected on a higher level of their safety culture.

Interpretation of determinants of safety culture for manufacturing engineering enterprises based on company size Interpretation of results of determinants of safety culture in terms of company size for the group of manufacturing engineering enterprises by using point graph (Fig. 3) shows a complex representation of a given relationship. It is clear that the scope of values of individual determinants of safety is considerable, point values are between 3.44.55. As part of a more complex evaluation of level of safety culture in mechanical enterprises, we divided a sample of respondents into groups based company size because we expected differences in terms of approaches towards OHS. The following can be also noted from results from graphs in Fig. 3. When evaluating levels of safety culture based on company size, we note the following:

- Determinant no. 1 - safety policy is evaluated as high (4.3-4.5) irrespective of the size of the enterprise. We presume that this is due to the fact that safety policies are prescribed by legislation and enterprises care to comply with given requirements.

- Evaluation of determinants no. 9 (ensuring safety) and no. 10 (participating in safety) in enterprises of all sizes is high (4.3-4.5), which is probably due to the fact that respondents evaluated their own behaviour and they evaluated it very positively.

- Determinant no. 3 - motivation for OHS reached between 3.8-4.1 points in companies of all sizes, which means lower level. Also, lower level was in determinant no. 6, employee involvement (3.7-4.0). 
- An interesting situation occurred with determinant no. 4 (education), where evaluation showed better results in category of $\mathrm{M}$ (medium) and $\mathrm{S}$ (small) enterprises, specifically 4.1-4.3. On the contrary, evaluation of these determinants in $L$ (large) enterprises reached only level 3.9, which we consider to be the lowest value.

- Determinants no.7 (engagement of management) and no. 8 (management's responsibility) were evaluated higher in small and medium size enterprises than in large enterprises, that is 4.0-4.3. Determinant no. 8, management's responsibility scored especially low in large enterprises, at 3.4, which is the lowest point of evaluation in manufacturing mechanical engineering enterprises. We can deduce from this, that in large enterprises employees do not perceive management's involvement and their responsibility in terms of OHS positively and this is management's big weakness.

\section{DISCUSSION}

Based on results of the evaluation, we can state that our assumptions were confirmed, specifically that in manufacturing enterprises work processes are more complex in terms of safety compliance, which was also noticeable in higher evaluation of safety culture. It also confirmed our assumption that companies with higher number of employees have better set up OHS management processes, which was reflected in higher level of safety culture. When evaluating individual determinants, we found that Slovak enterprises are successful in terms of safety policies and ensuring compliance with applicable legislation, no improvements are required. When considering positive evaluation of determinants, it proved our assumptions that evaluation of safety compliance and participation in safety, where respondents evaluated their own actions, was rated highly.
In this case we can state that the evaluation was not entirely objective. We can generalize that evaluated enterprises have considerable gaps in motivation of employees towards OHS, where evaluation levels were the lowest. To improve motivation towards OHS, we suggest that enterprises focus on creating a focused motivational strategy, which will improve employees'conscientious motivation towards improvements in OHS. A motivational strategy aims to create a positive work environment and develop policies and approaches that lead to employees'higher productivity. Determinants focused on management's activities in OHS received negative evaluations, such as management's interest and responsibility. We presume that to improve these areas, management will need to improve their own activities and processes, which is difficult. In another discussion about results from the research, we compared selected enterprises based on radar graphs. Radar graphs are a common tool used in evaluation of level of safety culture for one or several subjects. For a more complex evaluation of results from our research, we did not consider it to be the most appropriate tool, as it does not allow us to compare results from many enterprises at the same time. For this analysis, we selected an enterprise with the highest number of points in individual determinants (marked as max) and an enterprise with the lowest number of points in individual determinants (marked as min.). We compared the best and worst scorer. The radar graph shows a relative level of points in relation to the middle. The number of data points (categories) determines the axis of values (in our research these are 10 determinants of safety culture) and a value of a point and its distance from the centre of the graph. Each category has its own axis originating from the centre of the graph. Figure 4 shows a line graph to compare levels of safety culture in the best (MME max) and the worst (MME min.) manufacturing mechanical engineering enterprise of evaluated ten determinants of safety culture.
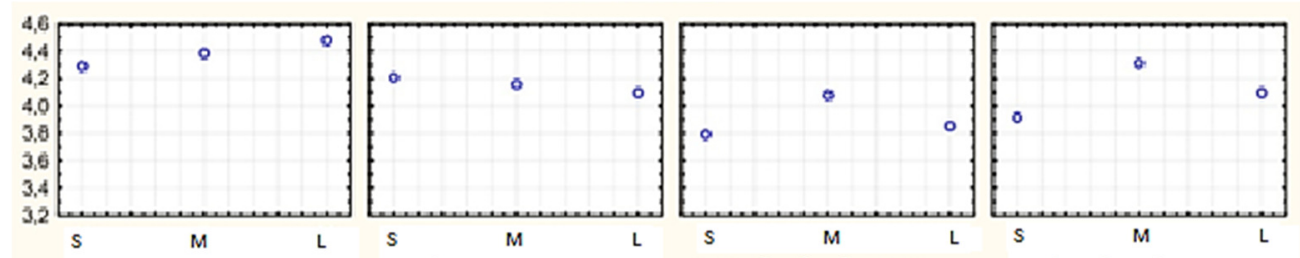

1. Company's safety polices 2 . Safety processes

3. Motivation for OHS 4. Education about OHS
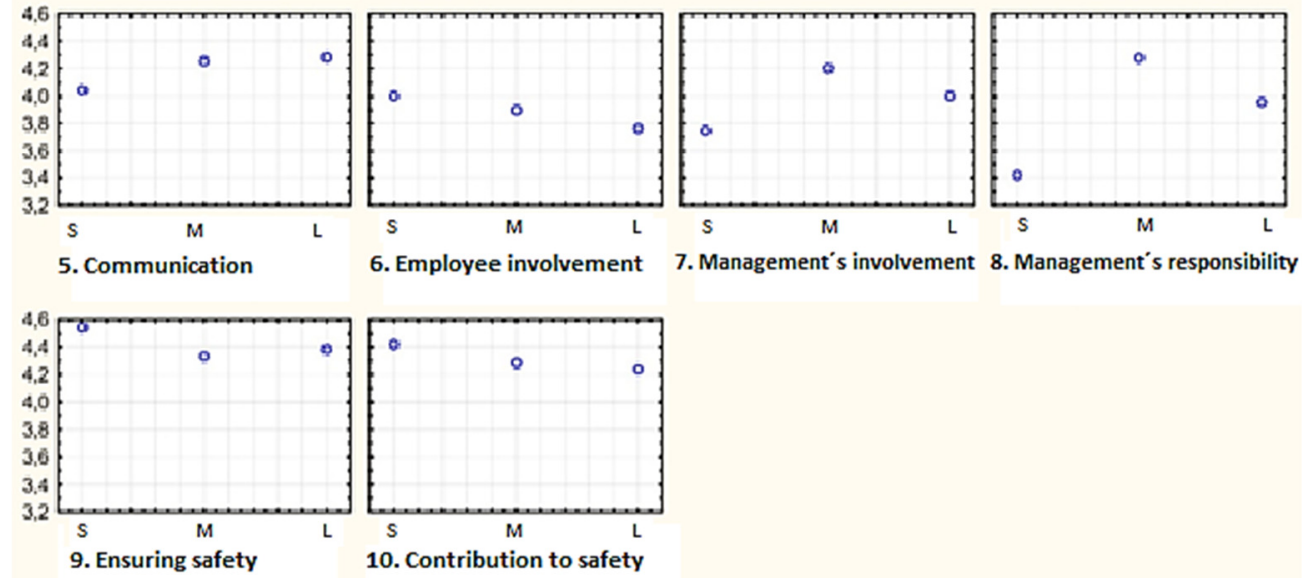

Fig. 3 Results of determinants evaluation of safety culture categorized by individual determinants 
Based on the results from Fig. 4, we can see the large difference between the best and the worst enterprise in terms of safety culture and in some determinants the differences are as high as 2 points (e.g.no. 1 safety policies, no. 3 motivation towards OHS). We once again see that motivation in both enterprises is lagging behind other determinants.

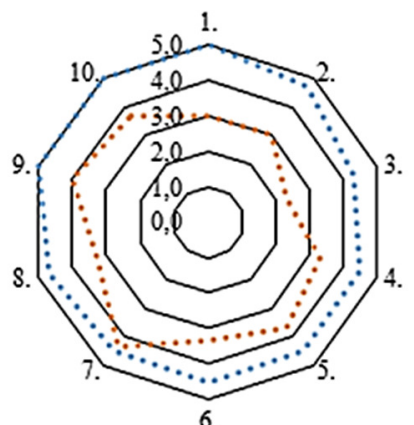

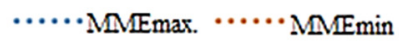

Fig. 4 Radar graph to evaluate level of safety culture for the best and the worst manufacturing mechanical enterprises

The best enterprise in the MME category is in large enterprises (has 268 employees) and produces aluminium profiles for the automotive industry. We can see from the results that aside from determinant no. 3, motivation, (4.3. points), all other evaluated areas are evaluated highly, surpassing 4.5 points and in determinants no. 1, 9, 10 reach maximum points, five. On the contrary, the lowest score received a small size manufacturing mechanical engineering enterprise that had 8 employees. In this enterprise, only determinant no. 7, management's interest, was higher than 4.0, specifically 4.2. Other areas were evaluated below the 4.0 point.

\section{CONCLUSIONS}

It is important to state that creation and building of a safety culture fundamentally influences improvement in safety and health protection, it simplifies many complicated processes in this area and provides targeted motivation for employees to complete tasks related to OHS. Based on the conducted research, we can conclude that level of safety culture in Slovak enterprises does not meet the required level and there are many gaps when fulfilling individual determinants. Our findings confirm that evaluations of determinants that are anchored in Slovak legislation, specifically safety policies, processes and education in OHS, have the most positive results. However, areas such as employee motivation, management's responsibility and interest did not receive positive results. Based on result of our research we confirm that by improving management's approach to building a safety culture, an organization will see improvement in employee motivation. In this case willingness to change will have a positive and important influence. Managers need to realize that only satisfied and positively motivated employees, who feel safe and unharmed, can produce at maximum and responsibly complete work tasks. It states in $\mathrm{OHS}$ that employees are the most important asset of each organization. Managers'roles, in terms of OHS, are to support, motivate and make employees'activities more attractive, which leads to positive results, improvement of understanding of safety, lower accident rate, illness and attrition.

\section{ACKNOWLEDGMENT}

The authors would like to thank Agency KEGA for their support of the KEGA 011TU Z-4/2017 project "Integration of progressive information technologies and soft-skills in education programs focusing on management of production processes".

This article was created as part of the project.

\section{REFERENCES}

[1] H. Alavi and P. Habek. "Optimizing outcome in the university - industry technology transfer projects". Management Systems in Production Engineering, vol. 22, no. 2, pp. 94-100, 2016.

[2] I. Fedorycheva and M. Hammer. "A description of methods and techniques of safety culture research". MM Science Journal, no. 4, pp. 768-771, 2015.

[3] R. Hnilica, M. Jankovský, M. Dado, V. Messingerová, M. Schwarz and D. Veverková. "Use of the analytic hierarchy process for complex assessment of the work environment". Quality \& Quantity, vol. 51, no. 1, pp. 93-101, 2017.

[4] Health and Safety Executive. ACSNI Study Group on Human Factors: Third Report - Organising for Safety. HSE Books, 1993.

[5] International Atomic Energy Agency (2009). Safety Standards The Management System for Nuclear Installations. [On-line]. Available: http://www.pub.iaea.org/MTCD/publications/PDF/Pub1392_web.pdf.

[6] L'. Simanová and P. Gejdoš. "The process of monitoring the quality costs and their impact on improving the economic performance of the organization". Enterprise Management, no. 3, pp. 172-179, 2016.

[7] I. Slováčková. "Proč a jak měřit kulturu bezpečnosti ve firmě". Bezpečnost' práce v praxi, no. 4, 2015.

[8] I. Tureková and Z. Turňová. "Assessment of human factor in production engineering", in Proc. of the 9th International Symposium on Occupational Safety and Hygiene, 2013, pp. 567-571.

\section{MSc. Erika Sujová, PhD.}

Assoc. Prof. MSc. Helena Čierna, PhD.

Technical University in Zvolen,

Faculty of Environmental and Manufacturing Technology Department of Manufacturing Technology and Quality Management

Študentská 26, Zvolen, 960 53, Slovak Republic

e-mail: erika.sujova@tuzvo.sk helena.cierna@tuzvo.sk 